\title{
MARX COMO REFERENCIAL PARA ANÁLISE DE RELAÇÕES ENTRE CIÊNCIA, TECNOLOGIA E SOCIEDADE
}

\section{Marx as an analytical framework for relationships between science, technology and society}

\author{
Paulo Lima Junior ${ }^{1}$. Diomar Caríssimo Selli Deconto ${ }^{2}$. \\ Ricieri Andrella Neto ${ }^{3}$. Cláudio José de Holanda Cavalcanti ${ }^{4}$. \\ Fernanda Ostermann ${ }^{5}$
}

Resumo: Ao longo das últimas décadas, a questão das relações entre ciência, tecnologia e sociedade vem se tornando cada vez mais importante para o desenvolvimento de novos currículos e práticas em educação científica. Este trabalho apresenta um referencial para análise de relações CTS baseado na obra "O Capital" de Karl Marx. Ele introduz conceitos e proposições fundamentais para se perceber de que maneira a introdução de inovações científicas e tecnológicas no mercado está relacionada à produção de capital, e como essa relação pode ser analisada criticamente, já que essas revoluções tecnológicas podem contribuir para a degradação das condições de existência da classe trabalhadora. Este referencial pode ser amplamente utilizado na formação de professores e no planejamento de currículos CTS que busquem uma perspectiva crítica e consistente das relações de exploração que estão nos fundamentos do modo de produção capitalista.

Palavras-chave: Relações CTS. Capitalismo. Marxismo.

\begin{abstract}
Over the past decades, relationships between science, technology and society have become increasingly important for the development of new curricula and practices in science education. This paper presents a framework based on "Das Kapital" for analyzing STS relations. It introduces fundamental concepts and propositions to understand how scientific and technological innovations are related to the production of capital and how to analyze this issue critically, since the technological revolutions these innovations imply may contribute to the subjection of the working class. This framework may be introduced in teacher education and STS curriculum planning aiming to reach some critical perspective on the relations of exploitation that underlie the capitalist mode of production.
\end{abstract}

Keywords: STS Relations. Capitalism. Marxism.

\footnotetext{
${ }^{1}$ Universidade Federal do Rio Grande do Sul (UFRGS), Instituto de Física. Av. Bento Gonçalves 9500, caixa postal 15051, CEP: 91501-970, Porto Alegre, RS, Brasil. E-mail: paulolima@ufrgs.br

${ }_{2,3,4,5}$ Universidade Federal do Rio Grande do Sul (UFRGS), Instituto de Física, Porto Alegre, RS, Brasil.
} 


\section{Introdução}

Ao longo das últimas décadas, a questão das relações entre ciência, tecnologia e sociedade (CTS) vem se tornando cada vez mais importante para o desenvolvimento de novos currículos e práticas em educação científica. Desde meados do século XX, currículos com ênfase em CTS são desenvolvidos em vários países, sobretudo nos países capitalistas centrais, como crítica à visão ingênua de que desenvolvimento científico e tecnológico implica sempre a melhoria do bem-estar social por meio do progresso econômico (AULER; BAZZO, 2001; CEREZO, 1998; MARTINS, 2002). Essa visão idealizada da tecnologia pode estar sendo incentivada pelos próprios professores da área de Ciências da Natureza. A saber, a concepção que parece ser dominante entre esses professores sustenta que a tecnologia é, fundamentalmente, uma aplicação das ciências (FIRME; AMARAL, 2008; FOUREZ, 2003; RICARDO; CUSTÓDIO; REZENDE JR., 2007). Afirmar que a ciência precede a tecnologia ou que a tecnologia é subordinada à ciência, além de não ser historicamente verdadeiro ${ }^{6}$, significa negligenciar, entre outras coisas, as implicações sociais da tecnologia. Assim, não se possibilita um olhar crítico a seu respeito e, como argumentam Ricardo, Custódio e Rezende Jr. (2007), isso pode levar os alunos a assumirem essa pretensa aplicabilidade e "utilidade" das ciências como sendo sempre benéficas. Tal postura pode estimular neles uma visão indesejável, fantasiosa e apologista da tecnologia.

O movimento CTS teve origem entre as décadas de 1960 e 70, em parte, em decorrência dessa necessidade de se lançarem olhares mais críticos sobre a atividade científicotecnológica. A partir da reflexão sobre as implicações militares da Ciência e da Tecnologia (C\&T), sobre a degradação ambiental e sobre o modelo linear de desenvolvimento - modelo em que se acredita que o desenvolvimento científico gera mais desenvolvimento tecnológico econômico e social, sucessivamente -, o status positivo da C\&T começou a ser questionado e os estudos dos aspectos sociais da C\&T tiveram seu início (BAZZO; LINSINGEN; PEREIRA, 2003).

Possivelmente por influência de o movimento CTS ter surgido nos países capitalistas centrais - que possuem uma tradição democrática maior do que a brasileira -, os temas mais frequentemente evocados em currículos CTS tendem a ser polêmicos e evidenciar o poder de influência que os estudantes podem ter enquanto cidadãos tomadores de decisão. Auler e Bazzo (2001), problematizando o contexto brasileiro, destacam que o movimento CTS poderia contribuir, fundamentalmente, para o desenvolvimento e consolidação de uma cultura de participação no Brasil.

Conforme von Linsingen (2007) os estudos CTS, desde o início do seu surgimento, se desenvolveram em três domínios: da pesquisa, das políticas públicas e da educação. No contexto educacional, os objetivos dos trabalhos que aparecem na literatura nem sempre conver-

\footnotetext{
${ }^{6}$ Por exemplo, os primeiros artefatos mecânicos criados, pelos romanos, com objetivos bélicos ou direcionados a obras de infraestrutura, as primeiras concepções de máquinas térmicas pelos gregos, não eram precedidos por um conhecimento científico formal e estruturado. Pelo contrário, foram necessários quase dois mil anos de progressos teóricos para que se tornasse possível explicar o funcionamento desses equipamentos. 
Marx como referencial para análise de relações ...

gem, refletindo as diferentes formas de se conceber este movimento (MARTINS; FERNANDES; ABREU, 2010). Embora os trabalhos possam aparecer com diversos enfoques, Cerezo (1998) sintetiza o movimento CTS como uma diversidade de programas interdisciplinares que, enfatizando uma dimensão social em C\&T, compartilham: (1) o rechaço da imagem da ciência como atividade pura; (2) a crítica à concepção de tecnologia como ciência aplicada e neutra; (3) crítica à tecnocracia.

Por outro lado, Aikenhead (1994) defende que uma perspectiva CTS tem como principal objetivo promover uma Alfabetização Científica e Tecnológica (ACT), auxiliando o aluno a construir conhecimentos, habilidades e valores necessários para tomar decisões responsáveis sobre questões de C\&T na sociedade e atuar na solução de tais questões. Como é possível perceber, esse objetivo geral se alinha com o que Auler e Delizoicov (2001) chamaram de alfabetização cientifica ampliada, onde os conteúdos não são trabalhados como se tivessem um fim em si mesmos, mas são apresentados com o propósito de fornecer subsídios para o aluno compreender e se posicionar frente a temas sociais relevantes.

Ao mesmo tempo em que distinguem a alfabetização científica ampliada de um ensino de conteúdos científicos desligado do plano social, Auler e Delizoicov (2001) apontam que os pontos de vista dos professores encontram-se eventualmente construídos em torno de três mitos fundamentais que precisam ser criticados sob uma abordagem CTS. A saber, os mitos são os seguintes:

(1) O mito da superioridade do modelo de decisões tecnocráticas refere-se à falsa crença de que as decisões sociais devem ser tomadas pelos especialistas, pois acredita-se que estes podem ser neutros, livres de interesses e convicções pessoais, podendo, portanto, tomar decisões imparciais e mais eficazes que outros indivíduos da sociedade.

(2) A perspectiva salvacionista da C\&T refere-se à crença de que todos os problemas sociais podem ser resolvidos pelo desenvolvimento científico e tecnológico, ou seja, para sanar os problemas da sociedade, basta investir em mais ciência e mais tecnologia. Esse mito pode dar a falsa sensação, às pessoas, de que não precisam se preocupar com os problemas sociais, já que eles serão resolvidos pelo desenvolvimento tecnológico e científico.

(3) O mito do determinismo tecnológico consiste na hipótese de que as tecnologias têm uma lógica completamente autônoma de demandas sociais, podendo ser explicada sem referência à sociedade. Sob a perspectiva desse mito, é aceito que a tecnologia tenha efeitos sociais, mas é negado que ela seja social na sua origem. Enfim, segundo o enfoque determinista, o destino da sociedade dependeria de um fator exógeno não social (C\&T), que a influenciaria sem sofrer sua influência.

Este trabalho apresenta um referencial para análise de relações CTS baseado na obra "O Capital” de Karl Marx (2010), sobretudo no sentido de proporcionar a necessária discussão crítica das implicações sociais da tecnologia, normalmente ausente na educação científica formal. Em sua obra principal, Marx introduz conceitos e proposições fundamentais para se perceber de que maneira a introdução de novas tecnologias no mercado está relacionada à produção de capital, e como essas revoluções tecnológicas podem, por exemplo, contribuir para a degradação das condições de existência da classe trabalhadora. Enfim, recorremos aos três mitos identificados por Auler e Delizoicov (2001) como ferramenta heurística para destacar as potencialidades do referencial de Marx no contexto do movimento CTS. 


\section{O referencial Marxiano}

Em Marx (2010), encontram-se fundamentos teoricamente consistentes e historicamente consagrados para a compreensão crítica dos fundamentos da sociedade capitalista e suas correspondentes relações de produção e circulação de bens. Ao mesmo tempo, Marx (2010) se dedica à análise de como a introdução de novidades científicas e tecnológicas nos diversos ramos de produção está relacionada, na sociedade capitalista, à exploração da força de trabalho e à produção de capital. Assim, o referencial marxiano ${ }^{7}$ traz uma perspectiva importante para a análise crítica de relações CTS.

O conceito de mais-valia relativa é, em Marx, o mais instrumental para analisar as relações entre C\&T, capital e classe trabalhadora. Porém, para compreender esse conceito adequadamente, é preciso ter contato com algumas definições e argumentos anteriores que fazem parte dos fundamentos do referencial marxiano. Segundo Marx (2010, p. 16), a "célula econômica da sociedade burguesa é a forma de mercadoria, que reveste o produto do trabalho". Assim, o conceito de mercadoria é o ponto de partida de Marx.

\section{Mercadoria, valor e trabalho}

A mercadoria é, em primeiro lugar, um produto do trabalho que, por suas propriedades, satisfaz uma necessidade humana (seja diretamente, pelo consumo, ou indiretamente, por ser voltada à produção de outras mercadorias). Simultaneamente, o que caracteriza uma mercadoria é a possibilidade de ser trocada por outra. Assim, todas as mercadorias são necessariamente bens úteis e permutáveis.

É importante destacar que, embora sejam permutáveis entre si por valores determinados, enquanto bens úteis, as mercadorias não podem ser reduzidas umas às outras. Ou seja, no que diz respeito à necessidade humana que é satisfeita, uma cama não pode ser reduzida a um casaco; nem uma cadeira a uma mesa. Em consequência disso, o valor pelo qual se aceita trocar uma mercadoria não se pode deduzir rigorosamente das suas qualidades úteis ${ }^{8}$. Por exemplo, um colar de ouro e brilhantes não é mais caro que uma cadeira de madeira porque é mais útil! Assim, deve haver alguma característica material comum a todas as mercadorias que permita definir (ainda que aproximadamente) os valores pelos quais essas mercadorias são permutáveis.

\footnotetext{
${ }^{7}$ Tradicionalmente o adjetivo "marxista" designa os sucessores de Marx e o conjunto de toda sua obra intelectual e política. De fato, não é incorreto dizer que Marx inicion o marxismo sem ser ele mesmo um marxista, pois seus sucessores realizaram desenvolvimentos realmente originais que nem sempre concordam ou se reduzem aos escritos assinados por Marx. Por outro lado, o adjetivo "marxiano", usualmente definido em oposição ao adjetivo "marxista", é usualmente empregado para designar os trabalhos que mantêm relação mais estreita com a obra original de Marx (em oposição às reinterpretações e reelaborações de seus sucessores). Neste artigo, baseados fundamentalmente na obra O Capital (MARX, 2010), foram mantidas essas denominações. Apresentamos, portanto, um referencial marxiano, e não um referencial marxista.

${ }^{8}$ A propósito, essa impossibilidade lógica de deduzir o valor de uma mercadoria das suas qualidades úteis devese ao fato de que a utilidade de uma mercadoria está nas suas qualidades, enquanto o valor pelo qual ela é trocada no mercado é uma quantidade - e, jamais, qualidades podem ser completamente reduzidas a quantidades.
} 
Marx como referencial para análise de relações ...

Pra resolver essa questão, Marx (2010, p. 60) destaca que uma mercadoria "só possui valor porque nela está corporificado, materializado, trabalho humano", e essa característica de materializar trabalho humano é comum a todas as mercadorias. O trabalho humano que produz mercadorias é uma atividade social, pois os homens trabalham uns para os outros na medida em que produzem mercadorias distintas e as trocam entre si. Assim, segundo Marx (2010), o valor de uma mercadoria mede-se pela quantidade média de trabalho necessário para fabricar o bem (medido em dias, horas, minutos) em um dado contexto social e histórico?. Por exemplo, se cadeira e mesa permutam-se na proporção de 2 para 1, isto significa que deve ser necessário o dobro de trabalho para fabricar uma mesa em comparação com uma cadeira. Enfim, para Marx, o valor das mercadorias está na quantidade média de trabalho necessário para produzilas, e não nas qualidades úteis que encontramos nessas mercadorias.

\section{Dinheiro, capital e mais-valia}

O emprego mais evidente dado ao dinheiro no mercado é o de meio de circulação de mercadorias. Por exemplo, se uma costureira vende o produto do seu próprio trabalho para adquirir dinheiro e, com esse dinheiro, adquire bens que lhe são úteis (comida, móveis para casa, vale-transporte), vemos aí que o dinheiro está sendo utilizado simplesmente como um meio de troca. Esse emprego do dinheiro pode ser representado pela sequência MercadoriaDinheiro-Mercadoria (M-D-M) e, como é possível perceber, o propósito que move essa sequência é a satisfação de necessidades humanas básicas (de alimentar-se, vestir-se, ter onde morar, divertir-se).

Por outro lado, existem sujeitos que, tendo acumulado certa quantidade de dinheiro, investem-no na produção de mercadorias (adquirindo máquinas, mão de obra, insumos) de maneira que, vendendo essas mercadorias, recuperam, ao final, uma quantidade de dinheiro maior que a investida. Nesse caso, completamente distinto do anterior, o dinheiro não é empregado como meio de circulação de mercadorias, mas as mercadorias são produzidas como meio de trocar dinheiro por mais dinheiro. O dinheiro que circula dessa maneira (representada pela sequência D-M-D) é chamado capital.

Como a circulação D-M-D é necessariamente um meio de trocar dinheiro por mais dinheiro, a forma completa de expressar esse processo deve ser $\mathrm{D}-\mathrm{M}-\mathrm{D}^{\prime}$, com $\mathrm{D}^{\prime}=\mathrm{D}+\Delta \mathrm{D}$. A saber, o valor excedente $\Delta \mathrm{D}$ que se acrescenta ao capital $\mathrm{D}$ ao final do processo D-M-D' é chamado mais-valia. Enfim, o motor da forma de circulação do capital é diferente da necessida-

\footnotetext{
${ }^{9}$ Esse poderia ser considerado o axioma fundamental da análise de Marx sobre a economia: de que o valor das mercadorias é igual ao trabalho social médio necessário para produzi-las. Uma vez que compreendemos e aceitamos essa afirmação como verdadeira, todo o restante da teoria de Marx sobre relações de produção torna-se relativamente simples de argumentar. Vale destacar também que, embora Marx tenha apresentado um argumento lógico para introduzir o pressuposto da relação entre valor e trabalho, o fundamento real dessa afirmação é sua postura filosófica, que tem influenciado, por exemplo, a abordagem sociocultural em educação científica (STETSENKO, 2008), segundo a qual uma unidade de análise em ciências sociais (no caso, a mercadoria) não pode jamais ser dissociada da atividade humana concreta na qual ela é produzida.
} 
de que a costureira tem de alimentar-se e que o trabalhador do campo tem de vestir-se. O que caracteriza e motiva a circulação do capital e a produção de mais-valia é a intenção gananciosa de trocar dinheiro por mais dinheiro.

\section{A força de trabalho e seu valor}

Como a origem do valor das mercadorias é o trabalho, o valor excedente produzido na circulação do capital só pode resultar de trabalho humano ${ }^{10}$. Assim, para compreender o processo da produção da mais-valia, é fundamental conhecer o conceito de força de trabalho. Por força de trabalho ou capacidade de trabalho, Marx (2010, p. 197) se refere ao conjunto das faculdades físicas e mentais existentes no corpo e na personalidade de um ser humano, as quais ele põe em ação toda vez que produz mercadorias de qualquer espécie. Assim como um pequeno agricultor vai ao mercado vender seus legumes, o trabalhador livre ${ }^{11}$ vai ao mercado vender sua força de trabalho.

Para ser vendida como mercadoria, a força de trabalho deve possuir valor. Segundo Marx, dado um contexto histórico e social, o valor da força de trabalho é determinado pelo valor das mercadorias que o trabalhador e sua familia precisam consumir para produzir e reproduzi a força de trabalho desse trabalhador. Mas o que isso significa? Bem, todo trabalhador precisa de um lugar para morar, precisa vestir-se, alimentar-se, divertir-se. O trabalhador especializado, em particular, consome certas mercadorias ao longo do seu processo de formação. Essas mercadorias acrescentam seu próprio valor ao valor da força de trabalho que precisou consumi-las para operar (por essa razão, o valor da força de trabalho especializada é superior ao da não especializada). Além disso, é preciso que o trabalhador possa se reproduzir e oferecer sustento à sua família, garantindo a existência de novas gerações de trabalhadores. Enfim, existe, em cada contexto social e histórico, uma série de necessidades básicas do trabalhador que precisam ser atendidas simplesmente para que a classe trabalhadora continue existindo. $\mathrm{O}$ valor da força de trabalho é o valor capaz de satisfazer minimamente essas necessidades produtivas e reprodutivas.

\footnotetext{
${ }^{10} \mathrm{Em}$ atos de fala típicos da linguagem do cotidiano, podemos encontrar expressa a crença ingênua de que o dinheiro acumulado e investido (por exemplo, em ações da bolsa de valores ou poupança) se multiplica sozinho, e que, quando acumulamos muito dinheiro e abrimos um "negócio", estamos colocando o dinheiro para trabalhar em nosso lugar. Aceitando-se o pressuposto de que a origem do valor das mercadorias é o trabalho, essa visão não tem nenhuma sustentação. Ninguém pode acumular valor sem que alguém tenha trabalhado para produzir esse valor.

${ }^{11}$ Marx considera livre o trabalhador que: (1) não é escravo; e (2) está "livre" dos meios (ferramentas e insumos) que lhe permitiriam produzir bens úteis sem vender sua força de trabalho. Com efeito, essas duas condições são suficientes e necessárias para que a força de trabalho seja vendida no mercado. Como é possível perceber, essa definição irônica do "trabalhador livre" (principalmente no seu segundo sentido) é uma crítica contundente à ideia de que a característica principal do modo capitalista de produção é a liberdade.
} 
Marx como referencial para análise de relações ...

\section{Mais-valia e exploração da força de trabalho}

Até aqui, temos definido mais-valia e força de trabalho. Porém, de que maneira a mais-valia é produzida pela exploração da força de trabalho? Segundo Marx (2010), o valor excedente (mais-valia), que faz brilhar os olhos do capitalista, tem origem no prolongamento da jornada de trabalho além do mínimo necessário à manutenção da força de trabalho.

Com efeito, a jornada de trabalho pode ser dividida em duas partes: (1) na primeira parte, o trabalhador produz o valor da sua força de trabalho - que o capitalista está obrigado a devolver-lhe na forma de salário simplesmente para atender às necessidades mínimas desse trabalhador; (2) na segunda parte, o trabalhador, que já produziu o valor da sua força de trabalho, trabalha para o capitalista, produzindo mais-valia.

Uma questão crucial para a classe capitalista (cujo interesse fundamental é produzir mais dinheiro com o dinheiro que dispõe) é a de como aumentar a produção de mais-valia. Segundo Marx, há duas maneiras distintas de o capitalista aumentá-la: (1) pela intensificação ou prolongamento ainda maior da jornada de trabalho; (2) pela redução do valor da força de trabalho.

A mais-valia produzida pelo aumento absoluto da duração ou da intensidade da jornada de trabalho chama-se mais-valia absoluta. Por sua vez, o aumento na mais-valia que resulta da redução da fração da jornada de trabalho em que o trabalhador produz o valor da sua força de trabalho (mantendo-se constante a duração e intensidade absolutas da jornada), chama-se mais-valia relativa. Esses dois movimentos da mais-valia são fundamentalmente distintos e encontram-se representados no Quadro 1.

Quadro 1. Mais-valia absoluta e mais-valia relativa ${ }^{12}$

\begin{tabular}{|l|l|l|}
\hline $\begin{array}{l}\text { Mais-valia } \\
\text { absoluta }\end{array}$ & & $\begin{array}{l}\text { Ao se aumentar a duração e intensidade da jornada de trabalho, } \\
\text { mantendo-se fixo o valor da força de trabalho, aumenta-se a } \\
\text { produção de mais-valia. }\end{array}$ \\
$\begin{array}{l}\text { Mais-valia } \\
\text { relativa }\end{array}$ & & $\begin{array}{l}\text { Ao se reduzir o valor da força de trabalho, mantendo-se fixa a } \\
\text { duração da jornada de trabalho, também aumenta-se a produção de } \\
\text { mais-valia. }\end{array}$ \\
\hline
\end{tabular}

Fonte: Elaborado pelos autores.

O prolongamento e a intensificação da jornada de trabalho podem ser realizados, dentro dos limites da lei, por ordem direta do capitalista. Entretanto, a alteração do valor da força de trabalho é um processo complexo, que extrapola os limites individuais de cada fábrica e que envolve fundamentalmente a incorporação de inovaçôes cientificas e tecnológicas aos processos de produção de mercadorias.

\footnotetext{
${ }^{12}$ As barras, no Quadro 1, representam a duração de uma jornada de trabalho. A parte escura da barra representa a parte da jornada na qual o trabalhador produz o valor da sua força de trabalho enquanto a parte clara representa a fração da jornada de trabalho em que se produz mais-valia para o capitalista. Como é possível perceber na barra inferior, há, nos dois casos, aumento da produção de mais-valia por trabalhador por dia.
} 


\section{C\&T na produção da mais-valia relativa}

Qual é a relação entre a produção da mais-valia relativa e a incorporação de novas técnicas e novas tecnologias aos processos de produção de mercadoria? De que maneira inovações em C\&T contribuem para a redução do valor da força de trabalho?

Marx (2010) destaca que algumas inovações tecnológicas e científicas contribuem para a redução do valor da força de trabalho (e, em consequência disso, para a produção de mais-valia relativa) na medida em que implicam a redução do trabalho médio necessário para produzir as mercadorias consumidas pela classe trabalhadora. Como o valor da força de trabalho é igual ao valor das mercadorias que o trabalhador precisa consumir para produzir e reproduzir sua força de trabalho, o barateamento das mercadorias necessárias à classe trabalhadora (decorrente do aumento da eficiência dos meios de produção, que é correlativo à introdução de certas inovações científicas e tecnológicas) implica a possibilidade de que sejam pagos salários menores aos trabalhadores ${ }^{13}$, com benefício para o patrão.

Para compreender melhor essa questão, considere, por exemplo, que o valor diário necessário à produção e reprodução da força de trabalho de um operário empregado em jornada de 8 horas é produzido nas primeiras 6 horas do dia. Isso significa que 6 horas são, em média, o tempo em que precisa operar esta força de trabalho para produzir valor equivalente aos alimentos, às vestimentas, à moradia e a todas as outras mercadorias que esse trabalhador e sua família necessitam consumir em um dia. $\mathrm{Na}$ medida em que são aprimoradas as condições de trabalho com que se produzem os bens necessários ao trabalhador, na medida em que a produção dessas mercadorias essenciais passa a exigir menor gasto de força de trabalho pela incorporação de tecnologia, na medida em que a produção de alimentos, roupas e moradia tornam-se mais eficientes, o valor das mercadorias que o trabalhador precisa consumir para se refazer cai e, com elas, cai o limite mínimo do salário pago ao trabalhador: o valor da sua força de trabalho. Assim, a elevação da produtividade geral - sobretudo em setores que produzem artigos que serão consumidos pela classe trabalhadora - implica a redução do valor da força de trabalho, contribuindo para a produção de mais-valia.

É importante destacar que, até o presente momento, o referencial marxiano pode parecer congruente com o terceiro mito (do determinismo tecnológico) no sentido em que a tecnologia contribui para a produção de mais-valia (o que poderia ser interpretado como um efeito socioeconômico da tecnologia), mas ainda não está claro de que maneira processos sociais externos moldam e influenciam a produção de tecnologia. Assim, se parássemos por aqui, a $C \& T$ poderia ser considerada corretamente um fator exógeno que interfere na socieda-

\footnotetext{
${ }^{13} \mathrm{Em}$ geral, o que ocorre na produção de mais-valia relativa não é a redução nominal dos salários individuais (mesmo porque isso é proibido por lei em muitos países). O que se pratica, usualmente, no mercado é um reajuste salarial abaixo da desvalorização da moeda que, de maneira geral, não torna as condições de moradia e alimentação dos trabalhadores muito piores do que já eram, havendo, pelo contrário, alguns avanços sensíveis justamente em virtude da popularização de inovações tecnológicas (por exemplo, a possibilidade de adquirir dispositivos eletroeletrônicos e eletroportáteis que, em outro período, foram considerados artigos de luxo, tais como televisões, celulares e computadores).
} 
Marx como referencial para análise de relações ...

de, mas não sofre sua influência. Com efeito, segundo Dagnino (2008), muitos autores têm equivocadamente interpretado Marx e os marxistas como deterministas tecnológicos. Entretanto, como será possível perceber nas próximas páginas, essa interpretação é bastante questionável.

\section{Exemplos de inovações que contribuem para a produção de mais-valia relativa}

Não faltam exemplos de inovações científicas e tecnológicas que contribuíram para o aumento da eficiência em certos ramos de produção e, com isso, para a produção de mais-valia relativa. Embora muitas dessas inovações tenham seu lado "positivo" fortemente ressaltado na mídia, sua potencialidade de degradar as condições de existência da classe trabalhadora ainda é pouco percebida e discutida na educação científica. A internet, exemplo corrente de inovação tecnológica, tem intensificado e barateado a troca de informações entre empresas de todo o tipo, reduzindo o tempo necessário para a produção de mercadorias e prestação de serviços, facilitando a comunicação entre fornecedores, produtores e clientes, e liberando os trabalhadores especificamente envolvidos nos processos da comunicação burocrática.

Nos bancos, a questão da tecnologia também é fundamental. Há, progressivamente, um aumento das operações que podem ser feitas rapidamente por telefone, pela internet ou em caixas de autoatendimento, permitindo que os bancos possam atender um número cada vez maior de clientes sem aumentar proporcionalmente seu quadro de pessoal. De maneira análoga, no campo da educação, a internet tem permitido expandir a distribuição de títulos e certificados escolares, permitindo que cada professor atenda a uma quantidade superior de estudantes com o auxílio de tutores frequentemente menos especializados, cujo valor da força de trabalho é, portanto, inferior. Esse exemplo da expansão do sistema educacional por meio do ensino à distância, com adoção ampla de tutores para mediar a relação entre a grande quantidade de alunos e o professor - ilustra como a introdução de inovações tecnológicas em um ramo produtivo pode vir acompanhada de uma mudança organizacional tão crucial para o aumento da eficiência do trabalho quanto a inovação tecnológica propriamente dita ${ }^{14}$.

Inovações nas linhas de montagem - derivadas dos campos da eletrônica, da mecânica fina, da automação, da ciência dos materiais - têm contribuído para a produção de uma quantidade cada vez maior de mercadorias (por exemplo, eletrodomésticos, eletroportáteis, automóveis) sem que a quantidade de força de trabalho necessária aumente proporcionalmente. De fato, uma das consequências da redução de valor desses bens industriais é que, mesmo estando os reajustes salariais da classe trabalhadora frequentemente abaixo da desvalorização da moeda, é possível que os trabalhadores continuem adquirindo eletrodomésticos e eletroportáteis.

$\mathrm{Na}$ agricultura, a produção de alimentos transgênicos - questão controversa do ponto de vista dos impactos ambientais a ela associados - também traz fortes controvérsias se analisada sob o ponto de vista dos seus efeitos econômicos. Somente uma análise muito ingênua

\footnotetext{
${ }^{14} \mathrm{~A}$ isto poderíamos acrescentar que a tecnologia, ao lado de seus aspectos técnicos, não pode ser considerada desligada de seus aspectos culturais e organizacionais (PACEY, 1990).
} 
pode levar a crer que um aumento na produção de alimentos implica direta e simplesmente a redução da fome no país, e que o impacto ambiental é o único ou principal prejuízo que decorre da implantação dessa inovação na produção de alimentos. A fome em larga escala não resulta da falta de alimentos, mas da má distribuição dos alimentos produzidos ${ }^{15}$. Por outro lado, a redução do valor dos alimentos consumidos pelos trabalhadores implica a redução do valor da sua força de trabalho, e a redução do valor da força de trabalho, por sua vez, contribui para a produção da mais-valia relativa. Enfim, como o real motor da sociedade capitalista é a vontade gananciosa de trocar dinheiro por mais dinheiro, inovações científicas e tecnológicas tendem a ser empregadas em larga escala na medida em que representam alternativas economicamente mais rentáveis para o capitalista.

A classe dos capitalistas que investem seu dinheiro em plantações de feijão não é mais nobre por estar produzindo alimentos que vão para a mesa do trabalhador. Nem é por amor ao conhecimento ou à tecnologia que se decide implantar esta ou aquela inovação, mas porque sua implantação significa uma maior produção de mais-valia e uma mais eficiente exploração da classe trabalhadora.

A produção de mais-valia (relativa) é o lugar em que algumas inovações científicas e tecnológicas se encontram com as relações sociais da exploração capitalista em uma via de mão dupla. A questão da produção de mais-valia é sempre crucial para que um capitalista decida incorporar ou não inovações tecnológicas à sua produção, e o fato de que certas tecnologias são mais prontamente empregadas na produção de mais-valia do que outras influencia decisivamente nas direções em que avançam a ciência e a tecnologia ${ }^{16}$. Ao lado disso, a própria disponibilização de mais alimentos e alimentos mais baratos no mercado é uma questão estratégica para toda a classe capitalista. Afinal, caindo os preços do feijão, do arroz e da soja, caem os valores da força de trabalho e aumenta a flexibilidade de os empregadores definirem salários mais baixos para seus empregados.

Enfim, por suas implicações, o conceito de mais-valia relativa é instrumental para analisar relações entre $C \& T$ e sociedade, do ponto de vista da economia política:

(1) $\mathrm{Na}$ medida em que contribuem para o aumento da produtividade de mercadorias consumidas pela classe trabalhadora, inovações científicas e tecnológicas tornam possível a produção de mais-valia relativa, satisfazendo a ganância do capitalista;

(2) Devido ao capitalismo estar fundamentalmente relacionado à necessidade de trocar dinheiro por mais dinheiro, a contribuição para o bem-estar social que, eventualmente, emerge da introdução de C\&T nos meios de produção não é mais que um efeito colateral da necessidade de acumulação capitalista - a produção de mercadorias para o bem-estar social não é jamais um objetivo em si mesmo, mas um meio de acumulação.

\footnotetext{
${ }^{15}$ Tal ingenuidade se assemelha muito a concluir que o Brasil é um país rico baseando-se apenas na renda per capita. A quantidade de dinheiro disponível por habitante seria suficiente para prover boa qualidade de vida para todos. Mas é a má distribuição de renda um dos maiores problemas do Brasil e um dos fatores que levam muito dos habitantes do país a situações de extrema pobreza.

${ }^{16}$ Essa asserção, que será melhor explorada a seguir, permite problematizar o terceiro mito (do determinismo tecnológico).
} 
Marx como referencial para análise de relações ...

(3) Na medida em que se tornam instrumento de produção de mais-valia relativa, inovações científicas e tecnológicas passam a ser reguladas pela ganância de se produzir dinheiro com mais dinheiro que caracteriza o sistema capitalista - portanto, a tecnologia não é jamais completamente autônoma de fatores externos (sobretudo dos interesses dos capitalistas).

Como é possível perceber, as duas últimas implicações apresentadas são negações de dois dos mitos relacionados à neutralidade da C\&T (AULER; DELIZOICOV, 2001). São esses, respectivamente: (1) a "perspectiva salvacionista da C\&T", segundo a qual avanços tecnológicos implicam, em todo o caso, o aumento do bem-estar social; e (2) o "determinismo tecnológico", segundo o qual C\&T moldam a sociedade, mas não sofrem influências dela.

Figura 1. C\&T e as relações sociais de produção.

C\&T tornam as relações sociais de
produção mais eficientes com vistas à
produção de mais-valia.
$\begin{aligned} & \text { Contribuições para o bem-estar geral } \\ & \text { da população são efeitos colaterais do } \\ & \text { processo de acumulação capitalista. }\end{aligned}$

Fonte: Elaborado pelos autores.

A Figura 1 representa as relações desenvolvidas até aqui entre C\&T e o conjunto das relações de produção. Como é possível perceber, é impossível sustentar a afirmação de que o referencial de Marx é determinista tecnológico, ou seja, que a sociedade não influencia os desenvolvimentos da ciência e tecnologia. Enfim, quanto mais C\&T são incorporadas aos processos de produção, tanto maior será a produção de mais-valia relativa. Com efeito, não existe, em uma sociedade capitalista, lugar para a ciência e para a tecnologia fora da relação com o capital.

\section{Mecanização e industrialização}

O processo de produção de mais-valia relativa, certamente, é uma das questões mais difíceis de se compreender dentro do quadro marxiano. Entretanto, existem outras relações um pouco mais diretas entre $C \& T$, capital e condições de existência da classe trabalhadora que podem ser apontadas por uma análise do processo de industrialização das nações. 


\section{O valor que a máquina transfere para a mercadoria}

Por resultar de trabalho humano e por se consumir ao longo do processo de produção, a máquina acrescenta seu valor à mercadoria que produz na proporção do seu desgaste; e o valor da máquina, tal como em qualquer outra mercadoria, é fixado pela quantidade de trabalho necessário para produzi-la. Assim, em oposição ao mito de que inovações tecnológicas são fontes criadoras de valor, é preciso reconhecer, à luz do referencial marxiano, que a máquina, por si mesma, não transfere para a mercadoria valor além daquele que ela já continha ao entrar na fábrica, pois a diferença entre o valor dos meios de produção consumidos e o valor do produto final é sempre igual a uma porção de trabalho humano.

A quantidade de valor que a máquina transfere para a mercadoria depende, essencialmente, de duas coisas: (1) do valor da máquina, ou seja, do trabalho social médio necessário para produzi-la; e (2) da sua produtividade. O valor transferido para cada mercadoria é proporcional ao valor da máquina e inversamente proporcional à sua produtividade. A produtividade da máquina, por sua vez, está relacionada à liberação de força de trabalho. Quanto mais produtiva, mais força de trabalho a máquina libera e mais vantajosa ela é para o capitalista. Para ilustrar essa afirmação, Marx relata que:

\footnotetext{
Nas fábricas onde o velho método de estampar tecidos à mão foi substituído pela máquina, uma só máquina assistida por um adulto ou menor, estampa, em uma hora, a mesma quantidade de tecido a qua tro cores, tarefa que exigia antes 200 homens para ser realizada no mesmo tempo. (MARX, 2010, p. 448)
}

Atualmente, a adoção da internet (e outras tecnologias da comunicação) permite superar a limitação de um professor atender a somente algumas dezenas de estudantes. Porém, é necessário criar, em contrapartida, uma posição relativamente nova, que é a do tutor de ensino a distância, frequentemente menos especializado que o professor, tratando-se, portanto, de força de trabalho mais barata. O resultado final dessa transformação é o aumento da produção de títulos escolares sem um aumento proporcional da quantidade de professores.

Levando em consideração que, para o capitalista, a produção de mercadorias é tão somente um meio de produzir mais-valia, em que circunstâncias a mecanização torna-se vantajosa para o capital? Do ponto de vista do barateamento da mercadoria, a introdução de inovações científicas e tecnológicas é quase sempre vantajosa, pois, frequentemente, implica reduzir a quantidade de trabalho social médio necessário para produzir cada mercadoria. Porém, o capitalista típico só visa o barateamento do seu produto na medida em que ele significa um aumento da sua capacidade de extrair mais-valia. Assim, para o capital, a condição para que seja vantajosa a introdução de novas máquinas e ferramentas é que seu valor seja inferior ao valor da força de trabalho que ela libera (MARX, 2010, p. 448).

\section{Consequências da produção mecanizada sobre o trabalhador}

Frequentemente, a introdução de inovações científicas e tecnológicas simplifica o processo do trabalho, dispensando o uso de força física e tornando tal processo menos árduo. 
Porém, é duvidoso que o acréscimo de inovações ao processo de produção ocorra com o objetivo de tornar mais suave a labuta do trabalhador. Não é por amor ao trabalhador nem à tecnologia que se move o sistema capitalista. Com efeito, embora a produção de ciência e tecnologia possa ocorrer de maneira relativamente independente de processos econômicos (no sentido em que nem todas as demandas dos campos de produção de ciência e tecnologia podem ser efetivamente deduzidas de forças econômicas), uma inovação só entra no chão da fábrica quando representa vantagem para o capitalista nos termos discutidos até aqui.

Historicamente, a mecanização significou, em vários ramos da produção de mercadorias, dispensa da necessidade do uso de força e um aumento na demanda por motricidade fina (geralmente fornecida por mulheres e crianças). Assim, a mecanização dos meios de produção significou, em alguns momentos históricos, colocar toda a família do trabalhador - e não somente o homem adulto - sob o domínio do capital. O aumento da quantidade de trabalhadores disponíveis constituiu razão fundamental para que as condições de trabalho (salários, duração e intensidade da jornada de trabalho) fossem redefinidas com prejuízo para o trabalhador ${ }^{17}$. Em consequência disso, passaram os homens a explorar a força de trabalho dos filhos desde a infância. "Antes, vendia o trabalhador sua própria força de trabalho, da qual dispunha como pessoa livre. Agora, vende mulher e filhos" (MARX, 2010, p. 453).

\section{Elite técnico-científica}

Como já foi destacado, a introdução de inovações científicas e tecnológicas tende a simplificar o processo de trabalho com o propósito de aumentar sua produtividade segundo os interesses do capital. Como resultado, para gerar a mesma quantidade de produtos, é necessária, no chão da fábrica, uma quantidade progressivamente menor e menos especializada de trabalhadores. Tal mudança organizacional favorece, por outro lado, a consolidação de uma fração mais ou menos abastada da classe trabalhadora que é responsável pela produção e manutenção dessas inovações, e que goza de condições de trabalho significativamente diferentes (tais como cientistas, engenheiros, e outros profissionais altamente especializados da área de C\&T).

\footnotetext{
${ }^{17}$ Geralmente, quando um grande segmento da sociedade que se encontrava alijado do mercado (por exemplo, mulheres, jovens e certos grupos étnicos) ganha acesso a esse mercado, observa-se algum tipo depreciação dos detentores do monopólio. Por exemplo, segundo Marx (2010), a entrada de mulheres e crianças no mercado de trabalho, durante a primeira revolução industrial na Inglaterra, implicou uma ampla queda nos salários e intensificação da jornada de trabalho da classe trabalhadora (até então composta, predominantemente, por homens adultos) para benefício dos capitalistas. Uma vez que pais, mães e filhos da classe trabalhadora encontravam-se nas fábricas, a redução drástica dos salários não implicou dizimar completamente essas famílias que, apesar das mudanças, conseguiram continuar comendo, vestindo-se e aquecendo-se. Situação análoga ocorreu na segunda metade do século XX com a expansão do sistema de ensino em países como a França (e, mais tarde, em países como o Brasil). A ampliação do acesso de classes populares à escola implicou a desvalorização e inflação dos títulos escolares de maneira que, para um jovem ocupar os mesmos cargos no mercado de trabalho hoje, é geralmente necessário ter estudado mais que seus pais e avós (BOURDIEU, 2008).
} 
A assim chamada elite técnico-científica não se confunde com a classe capitalista, pois, em princípio, vende sua força de trabalho em troca de salário somente para satisfazer suas necessidades de comer, divertir-se, ter onde morar e o que vestir (ou seja, em princípio, usa o dinheiro como meio de circulação de mercadorias e não como capital). Porém, sendo o valor dessas forças de trabalho muito superior à do trabalhador de chão de fábrica, estes sujeitos sofrem, de maneira muito menos imediata, as pressões do capital e, justamente por isso, são menos propensos (e, às vezes, menos interessados) a tomar consciência das contribuições fundamentais da ciência e da tecnologia para manutenção e intensificação da exploração da fração menos favorecida da classe trabalhadora pelo capitalista.

A elite técnico-científica não está jamais completamente isenta dos interesses do capital, que a emprega e garante seus privilégios. As opiniões de cientistas, engenheiros e outros profissionais dos campos de C\&T não podem ser consideradas completamente isentas justamente em virtude da relação de cooperação (direta ou indireta, consciente ou não) que esses trabalhadores mantêm com a classe capitalista. Por exemplo, embora existam profissionais contrários, não é de surpreender que vários físicos e engenheiros nucleares defendam o uso, em larga escala, da energia nuclear. É justamente para esses profissionais que a expansão da matriz energética nuclear mais provavelmente representa maior empregabilidade e melhores oportunidades de trabalho.

Visto sob esse ponto de vista, quando se trata de decidir se certa inovação científica e tecnológica deve ou não ser levada à sociedade (o que geralmente significa incorporá-la a algum processo de produção), tem-se dois problemas de partida: (1) a elite técnico-científica está materialmente comprometida com a introdução de seus conhecimentos e técnicas nos processos de produção; e (2) os profissionais de C\&T que efetivamente têm voz em um processo de decisão são sempre selecionados com base em algum critério que jamais é completamente técnico, podendo estar a serviço do que é mais conveniente à classe capitalista e seus representantes (podemos chamar isso de eleição não técnica dos técnicos).

Como é possível perceber, as duas últimas implicações do referencial marxiano apresentadas aqui são negações do primeiro mito relacionado à neutralidade da C\&T (AULER; DELIZOICOV, 2001). Segundo o mito da "superioridade do modelo de decisões tecnocráticas”, profissionais de C\&T são neutros, livres de interesses e convicções pessoais, podendo, portanto, tomar decisões imparciais.

\section{Críticas ao referencial marxiano}

A obra de Marx é um clássico da sociologia e da economia, encontrando-se extensivamente descrita e analisada na literatura. Ela inspirou muitas pesquisas e ações políticas comprometidas com a superação das relações de exploração que estão nos fundamentos da sociedade capitalista. Por outro lado, assim como ocorre com todos os autores que são muito comentados, mas pouco lidos, Marx é frequentemente mal compreendido.

Em nenhum momento nega-se aqui a necessidade de se realizarem críticas e prolongamentos da obra de Marx - mesmo porque é justamente a esse projeto que muitos marxistas eminentes dedicaram suas vidas -, mas é preciso reconhecer que há críticas mais apressadas e 
Marx como referencial para análise de relações ...

que refletem uma compreensão mais superficial do referencial marxiano. Dessas, as principais são as acusações de Marx ser: (1) reducionista econômico; ou (2) determinista tecnológico. Essas críticas tornaram-se difundidas de tal maneira que é impossível abordar a obra de Marx sem discuti-las.

\section{Marx era um reducionista econômico?}

Uma das críticas mais apressadas que se pode fazer ao seu referencial é se tratar este de uma redução da relações sociais (com todos os aspectos emocionais, psicológicos, culturais e ideológicos que ela encerra) ao fenômeno econômico. De fato, a obra-prima de Marx (O Capital) é um livro de crítica à economia política. Porém, assim como escrever sobre Física não implica, automaticamente, sustentar que todas as leis da Química e da Biologia são dedutíveis de princípios Físicos, escrever sobre economia não significa, automaticamente, reduzir todo o fenômeno sociológico ao seu aspecto socioeconômico.

O que se pode dizer corretamente é que Marx dá bastante importância à dimensão econômica da relação social. Mas, esse peso é atribuído a partir de fundamentos históricos e filosóficos consistentes. Ao lado da dura realidade da classe trabalhadora nos primeiros países industrializados, Marx adota uma postura materialista - que não significa reduzir todos os fenômenos à sua dimensão econômica, mas implica reconhecer que anterior à sede de conhecimento, de arte, de criatividade, existe a sede de água e que, para amar e pensar, é preciso estar vivendo:

As premissas de que partimos [...] são os indivíduos reais, sua ação e suas condições materiais de existência, tanto as que eles já encontraram prontas, como aquelas engendradas de sua própria ação. [...] A primeira condição de toda a história humana é, naturalmente, os seres humanos vivos. (MARX; ENGELS, 2007, p. 10)

Uma evidência de que Marx não foi um reducionista econômico encontra-se em seu livro intitulado "O 18 Brumário de Luís Bonaparte" (MARX, 1968), no qual apresenta sua análise e crítica do golpe de Estado que coloca o sobrinho de Napoleão Bonaparte no poder. Ao longo dessa análise, Marx destaca a "liderança" de Luís Bonaparte e a força ideológica da figura de seu tio sem reduzi-las às relações econômicas de produção e troca de mercadorias.

Enfim, a produção e troca de mercadorias é, por excelência, a maneira de satisfazer as necessidades humanas mais básicas de alimentação, vestuário, residência, lazer. Portanto, o fator econômico é muito importante para se compreenderem vários aspectos da vida social humana. O resultado desse fato é que uma teoria econômica do fenômeno social - tal qual a teoria que Marx expressa em "O Capital" - goza de amplo escopo e torna-se pertinente para explicar aspectos fundamentais da vida do grande erudito (de necessidades intelectuais elevadíssimas) à do pobre morador de rua. Entretanto, ao lado disso, é preciso reconhecer que há muito, nos seres humanos e em sua organização social e histórica, que não se explica pelas lentes da economia. 


\section{Marx era um determinista tecnológico?}

Outra crítica geralmente dirigida a Marx (DAGNINO, 2008), e que muito interessa a uma apropriação de sua obra aos propósitos do movimento CTS, é a de que ele seria um determinista tecnológico. Nesse sentido, afirma-se que, em Marx, a relação entre tecnologia e sociedade é unidirecional, que a tecnologia determina o desenvolvimento da sociedade sem ser determinada por ela, que o destino da sociedade dependeria de um fator exógeno não social (C\&T) que a influenciaria sem sofrer sua influência. Essas afirmações ingênuas (jamais defendidas por Marx) estão intimamente ligadas à crença na neutralidade da ciência (AULER; DELIZOICOV, 2001), e serão analisadas aqui em dois níveis distintos (representados na Figura 2): (1) a tese de que C\&T determinam (univocamente) o desenvolvimento social; (2) a tese de que C\&T não são socialmente determinadas.

Figura 2. Representação gráfica das duas teses do determinismo tecnológico.

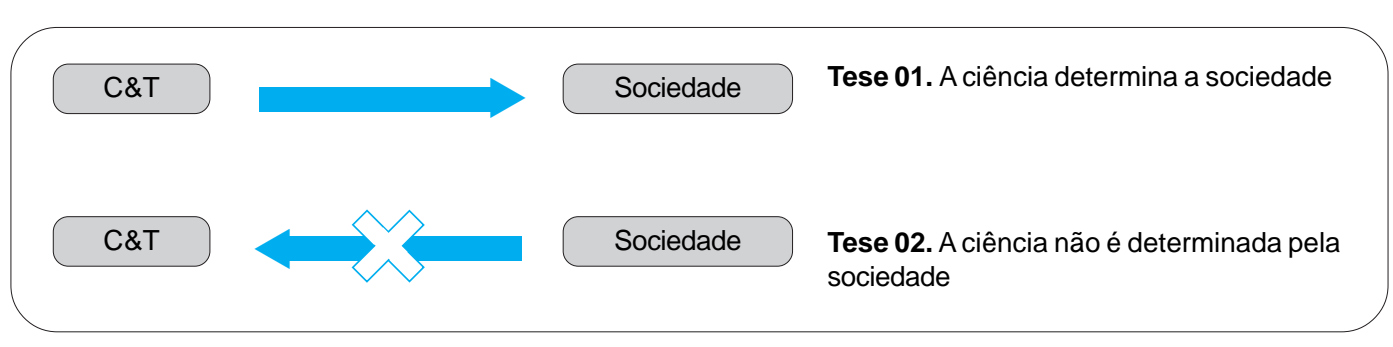

Fonte: Elaborado pelos autores.

É impossível discutir o determinismo tecnológico sem analisar o sentido e o emprego da "determinação" em ciências naturais e sociais. Em Física, quando dizemos que a trajetória de um projétil é determinada pelas suas condições iniciais (posição e velocidade) e pelas forças exercidas sobre esse projétil, estamos afirmando que, a menos das incertezas de medição, é possível predizer unívoca, completa e precisamente a trajetória do projétil a partir das forças exercidas e condições iniciais. Ou seja, se A é determinado por B, isso significa que saber B é suficiente para conhecer A em todos os seus detalhes. Em ciências sociais e, em particular, em Marx, o sentido das relações de "determinação" é sensivelmente diferente.

A sociedade, como Marx a entende, não pode ser separada do processo histórico objetivo de transformação da natureza e da própria vida social em vista de certas condições materiais; e, por essa razão, a tecnologia tem um papel fundamental na análise marxiana da sociedade. As referidas condições materiais (que podem compreender, por exemplo, os instrumentos e inovações tecnológicas disponíveis em um dado contexto) são necessárias, mas não 
Marx como referencial para análise de relações ...

suficientes, para a realização deste e daquele movimento na história da humanidade ${ }^{18}$.

$\mathrm{Na}$ perspectiva de Marx, é fundamental a ideia de que a ação humana transforma o mundo (natural e social) por meio de ferramentas que são dadas ao homem ou construídas por ele ao longo do processo histórico. Tais ferramentas expandem e limitam a ação humana, sem jamais determinar cada ação de maneira mecânica e imediata ${ }^{19}$. Com efeito, por mais determinantes que sejam a ciência e a tecnologia para o desenvolvimento da sociedade, o desenvolvimento (político, cultural, ideológico, econômico) das relações sociais ao longo da história não pode ser determinado unívoca, completa e precisamente por inovações tecnológicas.

Possivelmente por influência de o movimento CTS ter surgido nos países capitalistas centrais, os currículos CTS tendem a evidenciar o poder de decisão que os estudantes podem ter enquanto cidadãos. A questão da participação popular nos processos de tomada de decisão é evidentemente muito importante para Marx e os marxistas. Assim, é fundamental que os cidadãos se mobilizem e se posicionem com respeito a questões controversas, tais como: a importação de tecnologia para indústria, o uso militar e civil de energia nuclear, a implantação de hidrelétricas e a expansão da agricultura transgênica.

Entretanto, o referencial marxiano apresentado neste artigo permite argumentar que a participação popular em uma democracia capitalista geralmente preserva o capitalismo e, com ele, as relações de exploração que o caracterizam. Em outras palavras, embora seja importante discutir a questão dos transgênicos, entre um latifúndio em que se planta soja transgênica e outro em que se planta soja orgânica, encontram-se os mesmos sujeitos: capitalista e trabalhadores. Assim, embora algum leitor possa se surpreender com o poder da opinião pública, que, por exemplo, faz uma grande rede de fast-food acrescentar salada, frutas e iogurte ao seu cardápio, o referencial marxiano nos informa que muitas das conquistas populares em uma democracia capitalista se limitam a modificar os meios que o capitalista tem à sua disposição para a produção de mais-valia, preservando, entretanto, a exploração da classe trabalhadora. Dentro de uma democracia capitalista, os desenvolvimentos em C\&T são, em última análise, influenciados, regulados, moldados pela ganância da classe capitalista de trocar dinheiro por mais dinheiro (ver Figura 1). Essa ganância é, à luz do presente referencial, o verdadeiro motor da economia e elemento indispensável para a compreensão da ciência e da tecnologia em uma sociedade capitalista.

\footnotetext{
${ }^{18}$ Por exemplo, a primeira revolução industrial (que não compreende somente uma revolução nas técnicas de produção, mas todas as outras mudanças sociais e culturais que são correlativas à introdução em larga escala de novas técnicas e tecnologias no processo produtivo) jamais poderia se realizar sem o advento de certas inovações científicas e tecnológicas tal como a máquina a vapor. Observe que isso não equivale à afirmação (jamais realizada por Marx) de que a máquina a vapor, sozinha, teria produzido a revolução industrial! $\mathrm{Na}$ perspectiva de Marx (2010), a produção e a reprodução da máquina a vapor não estão jamais isentas do interesse capitalista de expandir a produção de mais-valia pelo aumento da eficiência do processo de produção. ${ }^{19}$ A propósito, essa ideia originalmente marxiana de que ferramentas (signos ou instrumentos) são fundamentais para se compreender a atividade humana pode se encontrar desenvolvida e atualizada explicitamente em referenciais modernos da psicologia, tais como: a teoria da ação mediada de J. Wertsch (1998) e a teoria da atividade histórico-cultural (ENGESTRÖM; MIETTINEN; PUNAMÄKI-GITAI, 1999).
} 


\section{Conclusão}

Como foi possível perceber ao longo deste artigo, a análise de inovações científicas e tecnológicas é fundamental para se compreender o funcionamento da sociedade capitalista, e os interesses da classe capitalista são igualmente importantes para se compreenderem os efeitos sociais das inovações científicas e tecnológicas.

Neste artigo apresentou-se um referencial para análise de relações CTS baseado na obra "O Capital" de Karl Marx (2010), que permite destacar como as inovações em C\&T podem contribuir para a degradação das condições de existência da classe trabalhadora. Os três mitos da neutralidade da ciência, apontados por Auler e Delizoicov (2001), foram retomados com o propósito de se destacarem as potencialidades do referencial de Marx no contexto do movimento CTS.

O conceito de mais-valia relativa é, na teoria do valor de Marx, o mais instrumental para analisar as relações entre C\&T, capital e classe trabalhadora. Porém, para compreender esse conceito verdadeiramente, foi preciso retomar algumas definições e argumentos fundamentais do referencial marxiano (tais como os conceitos de mercadoria, valor e capital). A retomada desses conceitos fundamentais permite perceber que o real motor da sociedade capitalista é a vontade gananciosa de trocar dinheiro por mais dinheiro, e que, portanto, inovações científicas e tecnológicas tendem a ser empregadas em larga escala somente na medida em que representam alternativas economicamente mais rentáveis para o capitalista.

A produção de mais-valia (relativa) é o lugar em que inovações científicas e tecnológicas se encontram com as relações sociais da exploração capitalista em uma via de mão dupla. A questão da produção de mais-valia é sempre crucial para que um capitalista decida incorporar ou não inovações tecnológicas à sua produção, e o fato de que certas tecnologias são mais prontamente empregadas na produção de mais-valia que outras influencia, decisivamente, nas direções em que avançam a ciência e a tecnologia.

Destacou-se, também, que a elite tecnocientífica está materialmente comprometida com a introdução de inovações científicas e tecnológicas nos processos de produção; e, por outro lado, que os profissionais de C\&T que têm voz em questões sociocientíficas controversas são geralmente eleitos com base em algum critério que jamais é completamente técnico, podendo estar a serviço do que é mais conveniente à classe capitalista e seus representantes.

Em vista de tudo isso, foi possível concluir que o referencial marxiano permite criticar os três mitos da neutralidade da ciência apontados por Auler e Delizoicov (2001), relembrando: (1) a superioridade do modelo de decisões tecnocráticas; (2) a perspectiva salvacionista da C\&T; (3) o determinismo tecnológico.

A variedade de contextos de aplicação do referencial marxiano a questões CTS é uma decorrência de ser a economia uma dimensão subjacente a todos os campos da atividade humana. Com efeito, acreditamos que este referencial pode ser amplamente utilizado na formação de professores e no planejamento de currículos CTS que busquem uma perspectiva crítica, consistente e profunda das relações de exploração que estão nos fundamentos do modo de produção capitalista. Além disso, ele pode ser muito importante na formulação de posicionamentos da comunidade de pesquisa em educação científica frente às políticas nacionais de ciência, tecnologia e inovação. 
Marx como referencial para análise de relações ...

\section{Referências}

AIKENHEAD, G. What is STS science teaching? In: SOLOMON, J.; AIKENHEAD, G. (Ed.). STS education: International perspectives on reform. New York: Teachers College Press, 1994. p. 47-59.

AULER, D.; BAZZO, W. A. Reflexões para a implementação do movimento CTS no contexto educacional brasileiro. Ciência \& Educação, Bauru, v. 7, n. 1, p. 1-13, abr. 2001.

AULER, D.; DELIZOICOV, D. Alfabetização científico-tecnológica para quê? Ensaio: pesquisa em educação em ciências, Belo Horizonte, v. 3, n. 2, p. 105-116, 2001.

BAZZO, W.; LINSINGEN, I.; PEREIRA, L. Introdução aos estudos CTS (Ciência, Tecnologia e Sociedade). Madri: Organização dos Estados Ibero-Americanos, 2003. (Cadernos de Ibero-América).

BOURDIEU, P. Classificação, desclassificação, reclassificação. In: NOGUEIRA, M. A.; CATANI, A. (Org.). Escritos de educação. Petrópolis: Vozes, 2008. p. 145-183.

CEREZO, J. A. L. Ciencia, tecnología y sociedad: el estado de la cuestión en Europa y Estados Unidos. Revista Iberoamericana de Educación, Madrid, n. 18, set.-dez. 1998. Disponível em:<http://www.rieoei.org/oeivirt/rie18a02.htm>. Acesso em: 16 nov. 2011.

DAGNINO, R. Neutralidade da ciência e determinismo tecnológico: um debate sobre a tecnociência. Campinas: Editora da Unicamp, 2008.

ENGESTRÖM, Y.; MIETTINEN, R.; PUNAMÄKI-GITAI, R.-L. (Ed.). Perspectives on activity theory. Cambridge: Cambridge University Press, 1999.

FIRME, R. D. N.; AMARAL, E. M. R. D. Concepções de professores de química sobre ciência, tecnologia, sociedade e suas inter-relações: um estudo preliminar para o desenvolvimento de abordagens CTS em sala de aula. Ciência \& Educação, Bauru, v. 14, n. 2, p. 251-269, ago. 2008.

FOUREZ, G. Crise no ensino de ciências? Investigações em Ensino de Ciências, Porto Alegre, v. 8, n. 2, p. 109-123, ago. 2003.

MARTINS, I.; FERNANDES, J. P.; ABREU, T. B. Uma análise qualitativa e quantitativa da produção científica sobre CTS (Ciência, Tecnologia e Sociedade) em atas do encontro de pesquisa em ensino de física (EPEF) no período de 1998 a 2008. In: ENCONTRO DE PESQUISA EM ENSINO DE FÍSICA, 2010, Águas de Lindóia. Anais... São Paulo: Sociedade Brasileira de Física, 2010 (1 CD-ROM).

MARTINS, I. P. Problemas e perspectivas sobre a integração CTS no sistema educativo português. Revista Electrónica de Enseñanza de las Ciencias, Vigo, v. 1, n. 1, p. 28-39, 2002.

MARX, K. O 18 de brumário de Luís Bonaparte. São Paulo: Escriba, 1968.

O capital: crítica da economia política. 27. ed. Rio de Janeiro: Civilização Brasileira, 2010. Livro I. 
Lima Junior, P. et al.

MARX, K.; ENGELS, F. A ideologia alemã. 3. ed. São Paulo: Martins Fontes, 2007.

PACEY, A. La cultura de la tecnología. Cidade do México: Fondo de Cultura Económica, 1990.

RICARDO, E. C.; CUSTÓDIO, J. F.; REZENDE JR., M. F. A tecnologia como referência dos saberes escolares: perspectivas teóricas e concepções dos professores. Revista Brasileira de Ensino de Física, São Paulo, v. 29, p. 135-147, mar. 2007.

STETSENKO, A. From relational ontology to transformative activist stance on development and learning: expanding Vygotsky's (CHAT) project. Cultural Studies of Science Education, Dordrecht, v. 3, n. 2, p. 471-491, 2008.

VON LINSINGEN, I. Perspectiva educacional CTS: aspectos de um campo em consolidação na América Latina. Ciência \& Ensino, Piracicaba, v. 1, p. 1-19, nov. 2007. (Número especial).

WERTSCH, J. V. Mind as action. New York: Oxford University Press, 1998.

Artigo recebido em 15/05/13. Aceito em 11/09/13. 